\title{
AN OPTIMUM FIRST MODAL SHAPE FREQUENCY FOR FLEXIBLE DISPLACEMENT AMPLIFIER MECHANISMS
}

\author{
NGOC THAI HUYNH ${ }^{1}$, TIEN V.T. NGUYEN ${ }^{2}$ \\ ${ }^{1}$ Faculty of Automotive Engineering Technology, Industrial University of Ho Chi Minh City \\ ${ }^{2}$ Faculty of Mechanical Technology, Industrial University of Ho Chi Minh City \\ huynhngocthai@iuh.edu.vn
}

\begin{abstract}
This investigation analyzed the influence of design variables of a new flexible hinge displacement amplification mechanism such as variable $\mathrm{L}, \mathrm{y}, \mathrm{t}, \mathrm{x}$ on the first modal shape frequency of this mechanism. The Taguchi method is based on finite element analysis in ANSYS to optimize the first modal shape frequency of this mechanism. The FEA outcomes indicated that design variables have significantly affected the first modal shape frequency of this mechanism. And the problem was verified by analysis of variance, analysis of the signal to noise, and regression analysis of frequency. The optimal outcomes of frequency obtained $85.268 \mathrm{~Hz}$. While the predicted outcomes of the frequency of the regression equation and the Taguchi method achieved $82.213 \mathrm{~Hz}$ and $82.459 \mathrm{~Hz}$, these results are good agreement with error deviation percent of $3.47 \%$ and $3.29 \%$, respectively.
\end{abstract}

Keywords: magnification mechanism, flexure hinge, Taguchi method, optimization.

\section{TỐI ƯU HÓA DẠNG TẦn Số RIÊNG ĐẦU TIÊN CHO CÁC CƠ CẤU KHUẾCH ĐẠI}

Tóm tắt. Trong nghiên cứu này, chúng tôi đã phân tích ảnh hưởng của các biến thiết kế (như là biến $L, y t$, $x$ ) cho cơ cấu khuếch đại đàn hồi đến tần số dao động riêng của cơ cấu. Phương pháp Taguchi dựa trên phân tích phần tử hữu hạn đã được chúng tôi sử dụng để tối ưu hóa tần số riêng của cơ cấu. Kết quả phân tích phần tử hữu hạn chỉ ra rằng các biến thiết kế ảnh hưởng mạnh đến tần số riêng của cơ cấu. Đồng thời, vấn đề này còn được xác minh bởi phân tích phương sai, phân tích tín hiệu ồn (noise signal) và phân tích hồi quy của tần số. Kết quả tối ưu của tần số đạt được $85.268 \mathrm{~Hz}$. Trong khi kết quả dự báo của phân tích hồi quy và Taguchi lần lượt đạt được $82.213 \mathrm{~Hz}$ và $82.459 \mathrm{~Hz}$, những kết quả này hoàn toàn thỏa mãn với kết quả số mà chúng tôi mô phỏng được với sai số cho phép lần lượt là $3.47 \%$ và $3.29 \%$.

Từ khóa: Cơ cấu khuếch đại, khớp đàn hồi, phương pháp Taguchi, tối ưu hóa.

\section{INTRODUCTION}

The study of the development of effective precision positioning mechanisms has challenges. Because of the essential need for state-of-the-art technologies in several industries, such as semiconductor manufacturing, where ultra-precise machining, and micro-electro-mechanical-systems (MEMS) are mandatory. For example, a $0.15-1(130 \mathrm{~nm})$ process on $300 \mathrm{~mm}$ silicon wafer has recently been developed and a $65 \mathrm{~nm}$ process will be realized soon. A new actuating mechanisms and control strategies are essential to overtake the current limitations and obtain a precision position in the nanometer range. One method of solving this kind of problem is to design new flexure hinges powered by piezoelectric actuators.

For decades, one of the most popular ideas in optimization literature is the idea that many flexure hinges were designed for many compliant mechanisms to eliminate the effects of clearance joints. The circular flexure hinge was designed for the 3-RRR compliant mechanisms, 3-DOF mechanism, and 3-DOF parallel mechanism [1-3], the stress distribution at all critical points, natural frequencies, and the corresponding modal shape were estimated and verified by experiment. The dynamic performance of the 3-DOF flexible mechanical system is determined by FEA and verified by experiments. $\mathrm{Xu}$ and $\mathrm{Li}$ [4] proposed a lot of optimum approaches to design compliant mechanism flexible hinge for many applications such as the Taguchi method, grey relational analysis, particle swarm optimization [5-10]. The shaped flexure hinges were designed for many applications as presented in reference [11]. The shaped flexure hinges obtained higher motion precision than the circular and V-shaped flexure hinge such as the general two-segment, 
circular-axis, symmetric flexure hinges was proposed by Lobontiu and Cullin [12] the new circular-axis flexure design was compared with the existing straight-axis right circular flexure hinge. The leaf flexible hinge was created by Qi et al. [13] the amplification ratio of the mechanism was determined and compared with existing methods and verified by the experiment. The Triple-LET and LET flexible hinge was manufactured by Qiu et al [14], Triple-LET flexible hinge can obtain $180^{\circ}$ without plastic deformation. Three traditional flexible hinges, filleted V-shaped flexure hinges, and cycloidal hinge were designed by Tian et al. [15], the closed-form compliance equations for filleted $V$-shaped flexure hinges was established and confirmed by FEA. Yang et al. [16] proposed the filleted leaf and circular flexible hinge, the static responses of the planar symmetric superplastic flexible hinge with different notches were analyzed and compared. The circular and leaf flexible hinges were applied to analyze static and dynamic for complex compliant mechanisms by Ling et al. [17], the static deformation and the modal shaped frequency were compared another existing theoretical method and FEA. Choi et al [18] designed and manufactured magnification mechanism model using flexure hinge and confirmed by the experiment.

\section{DESIGN THE STRUCTURAL MODEL AND METHODOLOGY}

\subsection{Flexible hinge and design model a new flexible displacement amplifier mechanism}

Some shapes of flexure hinge were designed and proposed by Y. Tian et al. [15] as presented in Figure 1 and Figure 2 [19]. The T-shape flexure hinge as presented in Figure 3 was designed by Kunhai Cai et al. [20]

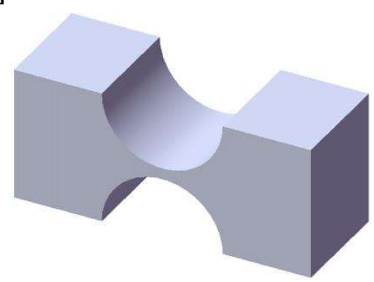

(a) Cicular hinge

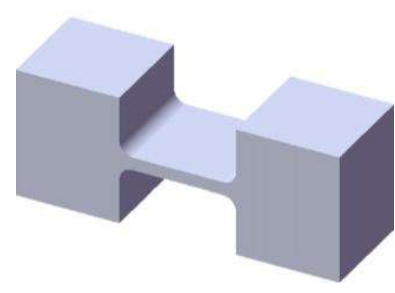

(b) Flexure hinge

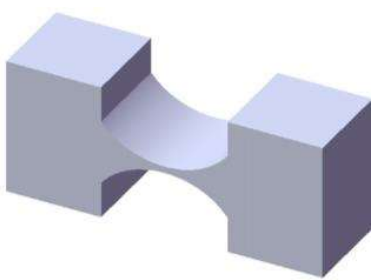

(c) Elliptical hinge

Figure 1. Three shape flexure hinge $[15,19]$

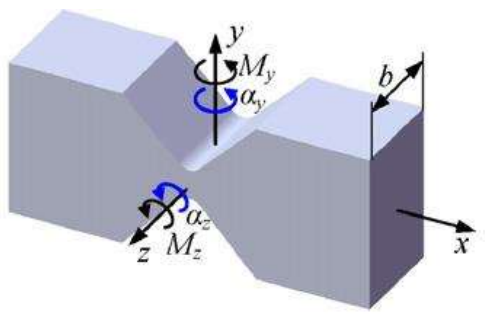

(a) 3D diagram of filleted $\mathrm{V}$-shaped hinge

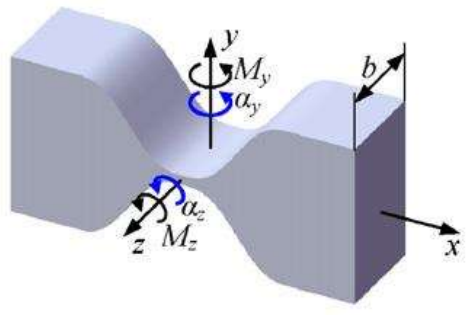

(c) 3D diagram of cycloidal hinge

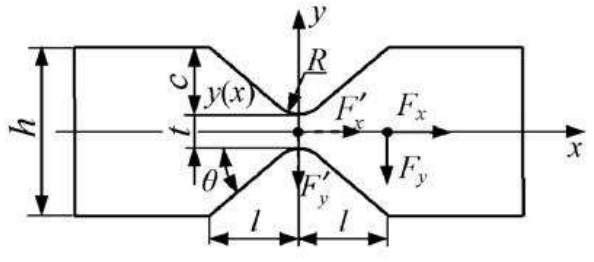

(b) 2D diagram of filleted V-shaped hinge

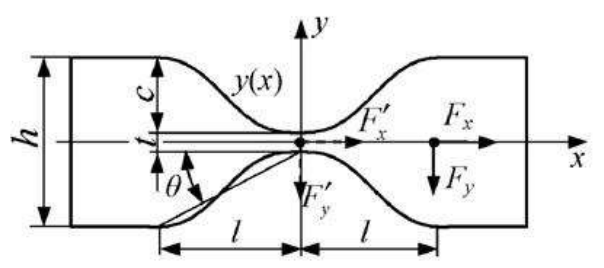

(d) 2D di agram of cycloidal hinge

Figure 2. Geometric parameters and loads of the FHs [15, 19] 


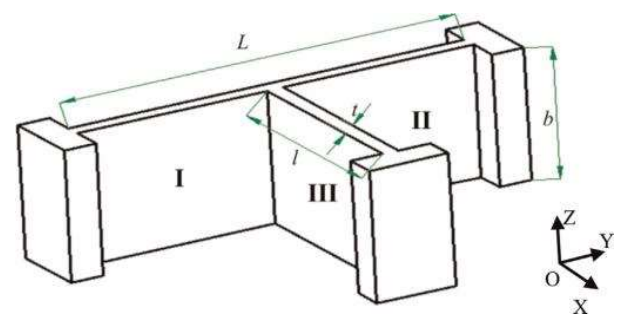

Figure 3. T-shape flexure hinge mechanism [20]

The flexible hinge was utilized in many compliant mechanisms. Because the flexible hinges are monolithic fabrication, no backlash and frictionless, lightweight. Therefore, it needs lubrication. To obtain a greater working range, a bridge-type compliant mechanism flexible hinge is utilized. The advantages of this mechanism are the high displacement amplification ratio, small size, small weight, high positioning accuracy, and high vibrated frequency. The flexible hinge displacement amplifier mechanism used one bridge-type and two L-shape lever-type [21].

The proposed mechanism has a high magnification ratio because the mechanism was designed by Two Lshape lever-type and one-half bridge-type mechanism. The flexible hinge of the proposed mechanism is subjected to tension and bending as analyzed in [22]. The proposed mechanism can be eliminated bending moment and lateral force by the symmetrical design of L-shape. The proposed mechanism has a high frequency and compact size. The proposed mechanism reduces the maximum stress by the half bridge-type compliant mechanism. The proposed mechanism was applied for the mechanisms requested high magnification ratio, high frequency, compact size, low stress and subjected to tension force and bending moment.

The mechanism has two L-shape lever-type and one bridge-type mechanism and leaf flexure hinge. The dimension and design variables of this mechanism as illustrated in Figure 4 with a dimension of 140 $\mathrm{mm} \times 132 \mathrm{~mm} \times 10 \mathrm{~mm}$. The mechanism has two L-shape lever-type and one bridge-type mechanism

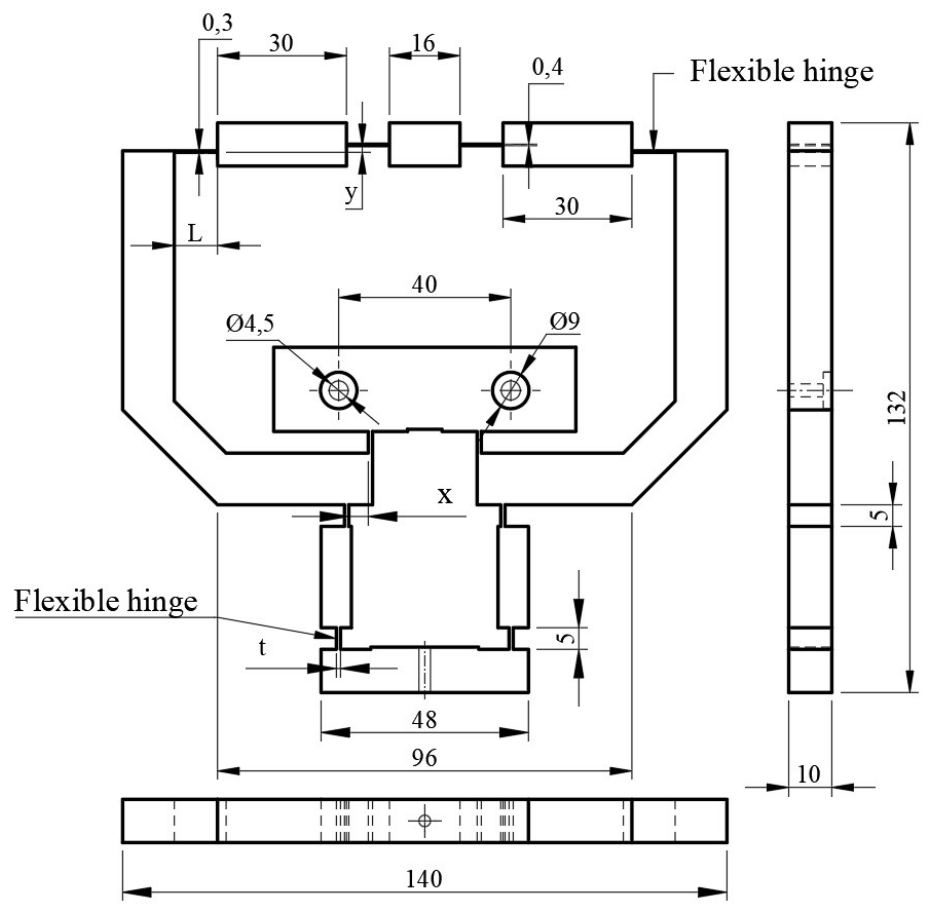

Figure 4. A new flexible displacement amplifier mechanism 


\subsection{Finite element model}

The material was used for the mechanism as listed in Table 1. First, the mechanism drew in Autodesk Inventor and then put into the Static structure of ANSYS. And then select material for the mechanism was aluminum AL-7075. The meshed mechanism was presented in Figure 5a with the number of nodes and the number of elements is equal to 130524 nodes, 73352 elements, respectively. The fixed support was utilized to fixed two holes on the mechanism and as presented the A surface, and input the displacement of 0.01 $\mathrm{mm}$ at input body as illustrated in the B surface according to y-axis direction as shown in Figure $5 \mathrm{~b}$.

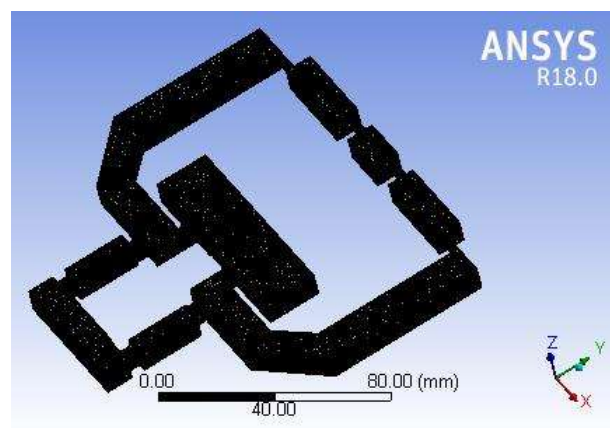

(a)

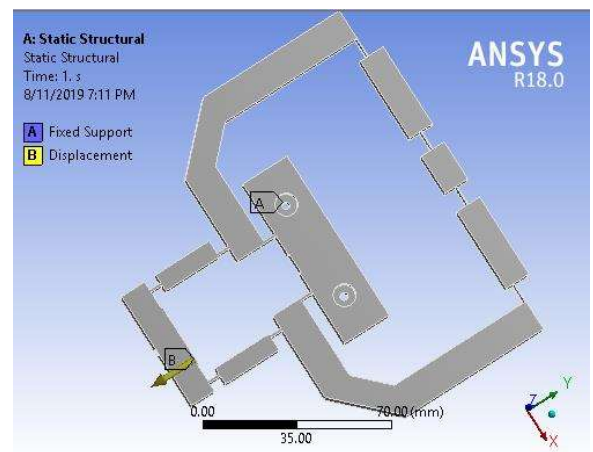

(b)

Figure 5. Meshing results (a) Meshing for the mechanism, (b) Boundary condition

Table 1: Mechanical properties of the material

\begin{tabular}{cccc}
\hline Material & Young's modulus (GPa) & Poisson's ratio & Yield (MPa) \\
\hline AL-7075 & 72 & 0.33 & 503 \\
\hline
\end{tabular}

\section{TAGUCHI METHOD}

In this study, we employed the Taguchi method (TM) in Minitab 18 software to create an orthogonal array. Firstly, the simulation output characteristics obtain in our investigation, which must meet the theory model. Then we will apply the optimal methods for the model to find out the best design for our studies. However, the deviations will be compared with the theoretical model which is very large, so the optimal methods cannot be approving. Therefore, in this investigation, we applied the Taguchi method based on grey relational analysis and artificial neural networks to optimize these output characteristics [5-10, 23-25].

First, choose optimization combination parameters for the output characteristics.

Secondly, design control factors and their levels.

Next, layout $\mathrm{L}_{27}$ orthogonal array

Finally, carry out simulation and collected simulation data.

"Larger is the better" approach:

$$
S / N=-10 \log \left(\frac{1}{n} \sum_{i=1}^{n} \frac{1}{y_{i}^{2}}\right)
$$

where $y_{i}$ is the observed data average at the $\mathrm{i}^{\text {th }}$ experiment, $\mathrm{n}$ is the quality of the experiment. In this investigation, $\mathrm{S} / \mathrm{N}$ analysis, analysis of variance, and regression equation.

\section{RESULTS AND DISCUSSION}

\subsection{Simulation Preparation}

In this investigation, four-length dimension was selected as four design variables with changed dimensions and was presented in Table 2 namely variable $L$ have two levels are $8 \mathrm{~mm}$ and $12 \mathrm{~mm}$, variable y has three levels are $1.2 \mathrm{~mm}, 2.4 \mathrm{~mm}$ and $3.6 \mathrm{~mm}$, variable thas three levels are $1 \mathrm{~mm}, 1.5 \mathrm{~mm}$ and $2 \mathrm{~mm}$ and variable 
$\mathrm{x}$ has three levels are $4.5 \mathrm{~mm}, 5.5 \mathrm{~mm}, 6.5 \mathrm{~mm}$. The orthogonal arrays and FEM outcomes were obtained from Minitab 18.0 and the FEM results in ANSYS as shown in Table 2. The first modal shape frequency outcomes were utilized to select one combination parameters that have maximum frequency by the Taguchi method. This method is one single-objective optimization.

Table 2: Parameters and their levels

\begin{tabular}{lccccc}
\hline \multirow{2}{*}{ Factor } & \multirow{2}{*}{ Unit } & \multicolumn{3}{c}{ Levels } \\
\cline { 4 - 6 } & & & $\mathbf{1}$ & $\mathbf{2}$ & $\mathbf{3}$ \\
\hline Flexible hinge length & $L$ & $\mathrm{~mm}$ & 8 & 10 & 12 \\
The vertical distance of two flexible hinges & $y$ & $\mathrm{~mm}$ & 1.2 & 2.4 & 3.6 \\
The thickness of the flexible hinge & $t$ & $\mathrm{~mm}$ & 1 & 1.5 & 2 \\
The horizontal distance of two flexible hinges & $x$ & $\mathrm{~mm}$ & 4.5 & 5.0 & 5.5 \\
\hline
\end{tabular}

\subsection{Effect analysis of variable $L$}

We obtain good results with this simple method of finite element method (FEM) by using ANSYS commercial software for simulation. It is clear to see that the output of the first modal shape frequency (Fre) of the mechanism slightly reduced from $47.468 \mathrm{~Hz}$ to $46.749 \mathrm{~Hz}$ therein variable L increases from $8 \mathrm{~mm}$ to $10 \mathrm{~mm}$, variable $\mathrm{y}, \mathrm{t}$ and $\mathrm{x}$ are equal to $1.2 \mathrm{~mm}, 1 \mathrm{~mm}$ and $4.5 \mathrm{~mm}$ as illustrated in Figure 6 and Table 3 . The obtained value of Fre is higher than the previous publication [21]. Overall, our method was the one that obtained the most robust results. The result is equal to or better than a result that is currently accepted.

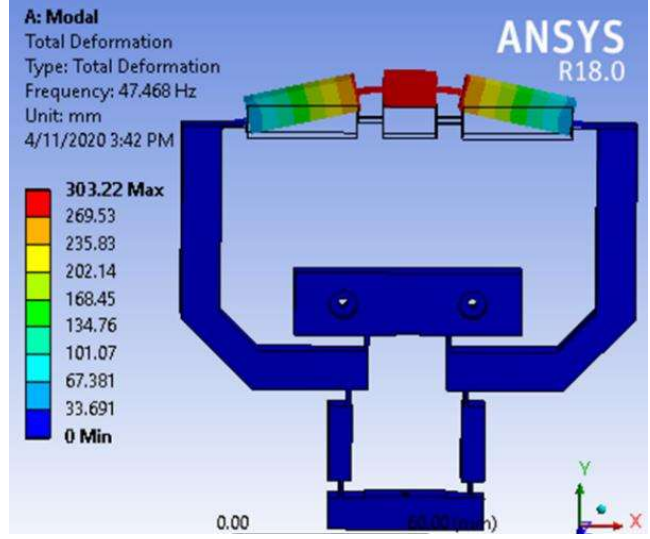

a) $\mathrm{L}=8 \mathrm{~mm}$

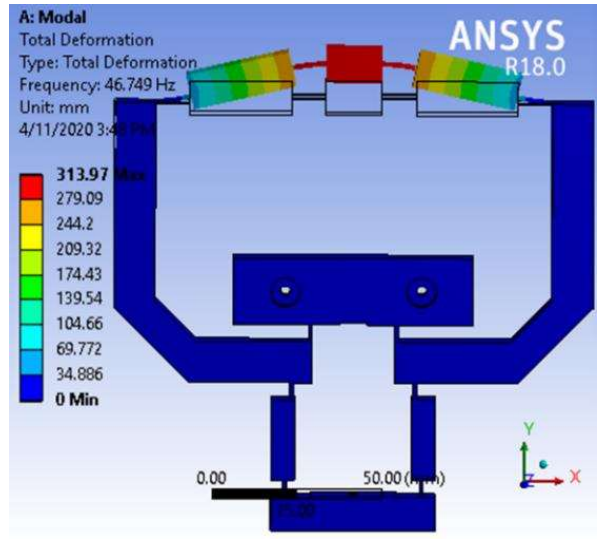

b) $\mathrm{L}=10 \mathrm{~mm}$

Figure 6. Effect of variable $L$ to deformation

Table 3: The outcomes of the analysis of the first mode shape frequency at different levels of variable $\mathrm{L}$

\begin{tabular}{clcccc}
\hline No. trial & \multicolumn{1}{c}{$\boldsymbol{L}$} & $\boldsymbol{y}$ & $\boldsymbol{t}$ & $\boldsymbol{x}$ & Fre \\
\hline 1 & 8 & 1.2 & 4.5 & 1 & 47.468 \\
2 & 10 & 1.2 & 4.5 & 2 & 46.749 \\
\hline
\end{tabular}

\subsection{Effect analysis of variable $y$}

Besides, several questions remain unanswered. However, we acknowledge that there are considerable discussions among researchers as to that the output Fre of the mechanism is significantly changed by variable y as depicted in Figure 7. These basic findings are consistent with research showing that the Fre value increased from $46.954 \mathrm{~Hz}$ to $61.97 \mathrm{~Hz}$ therein variable y increases from $1.2 \mathrm{~mm}$ to $3.6 \mathrm{~mm}$, variable $\mathrm{L}$, $\mathrm{t}$, and $\mathrm{x}$ are equal to $8 \mathrm{~mm}, 1 \mathrm{~mm}$, and $4.5 \mathrm{~mm}$, respectively. The obtained value of Fre is higher than the previous publication [21]. This is important to correctly interpret the results. 
Table 4: The outcomes of the analysis of the first mode shape frequency at different levels of variable $y$

\begin{tabular}{cccccc}
\hline No. trial & $\boldsymbol{L}$ & $\boldsymbol{y}$ & $\boldsymbol{t}$ & $\boldsymbol{x}$ & Fre \\
\hline 1 & 8 & 1.2 & 1 & 4.5 & 46.954 \\
2 & 8 & 2.4 & 1 & 4.5 & 53.611 \\
3 & 8 & 3.6 & 1 & 4.5 & 61.97 \\
\hline
\end{tabular}

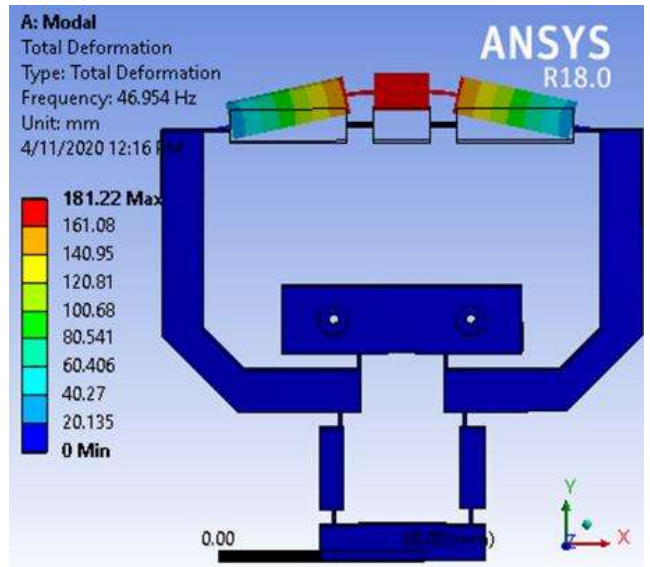

a) $y=1.2 \mathrm{~mm}$
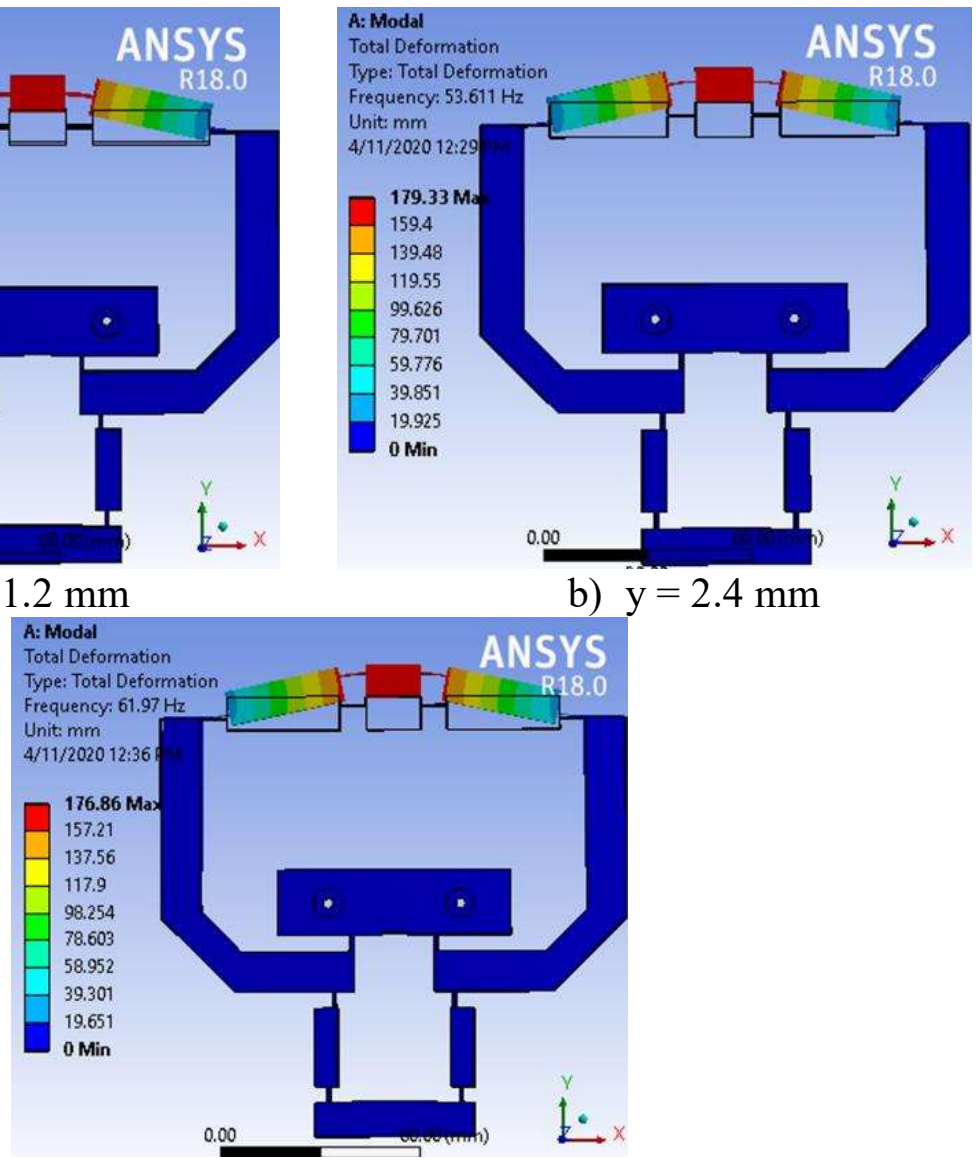

b) $\mathrm{y}=2.4 \mathrm{~mm}$

c) $\mathrm{y}=3.6 \mathrm{~mm}$

Figure 7. Effect of variable y to deformation

\subsection{Effect analysis of variable $t$}

Overall these findings are following findings reported by [25]. Here we compare the results of the proposed method with those of the traditional methods. The output Fre of the mechanism is significantly changed by variable $t$ as depicted in Figure 8. Because the Fre value increased from $50.9 \mathrm{~Hz}$ to $54.16 \mathrm{~Hz}$ therein variable t changes from $1 \mathrm{~mm}$ to $2 \mathrm{~mm}$, variable $\mathrm{L}$, $\mathrm{y}$ and $\mathrm{x}$ are equal to $10 \mathrm{~mm}, 1.2 \mathrm{~mm}$, and $5.5 \mathrm{~mm}$, respectively. The obtained Fre is higher than the previous studies. However, even better results are achieved when using our algorithm. Results demonstrate that this is not necessarily true.

Table 5 The outcomes of the analysis of the first mode shape frequency at different levels of variable $t$

\begin{tabular}{cccccc}
\hline No. trial & $\boldsymbol{L}$ & $\boldsymbol{y}$ & $\boldsymbol{t}$ & \multicolumn{1}{c}{$\boldsymbol{x}$} & \multicolumn{1}{c}{ Fre } \\
\hline 1 & 8 & 1.2 & 1 & 5.5 & 50.9 \\
2 & 8 & 1.2 & 1.5 & 5.5 & 52.789 \\
3 & 8 & 1.2 & 2 & 5.5 & 54.16 \\
\hline
\end{tabular}




\subsection{Effect analysis of horizontal distance of two flexure hinge ( $x$ )}

This section summarizes the findings and contributions made. Together, the present findings confirm that the output Fre of the mechanism is significantly changed by variable $\mathrm{x}$ as depicted in Figure 9. the variable $\mathrm{x}$ changes from $47.468 \mathrm{~Hz}$ to $50.731 \mathrm{~Hz}$, variable $\mathrm{L}$, y, and t are equal to $8 \mathrm{~mm}, 1.2 \mathrm{~mm}$ and $1 \mathrm{~mm}$, respectively. The results are higher than those of previous studies like [21]. These basic findings are consistent with research showing that the findings are directly in line with previous findings.

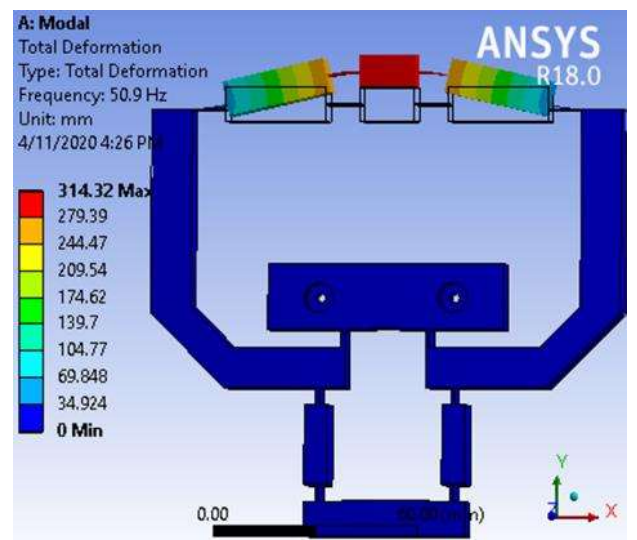

a) $\mathrm{t}=1.2 \mathrm{~mm}$

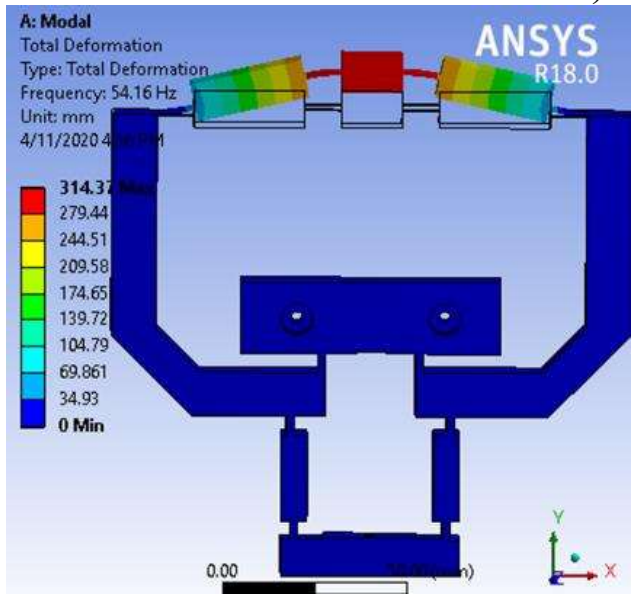

c) $\mathrm{t}=3.6 \mathrm{~mm}$

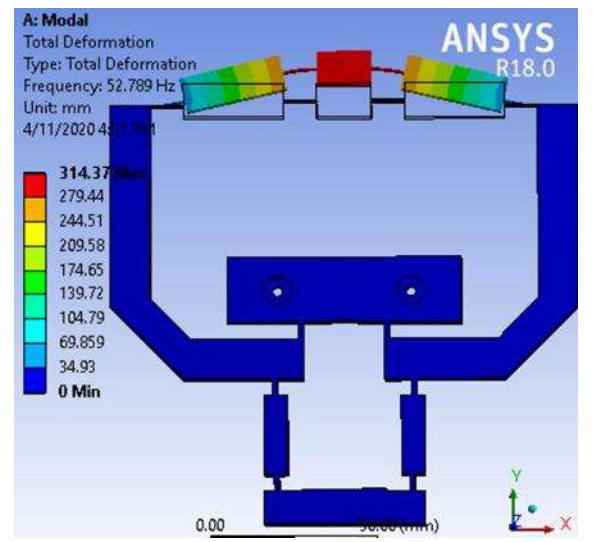

b) $\mathrm{t}=2.4 \mathrm{~mm}$

Figure 8. Effect of variable $\mathrm{t}$ to deformation

Table 6 The outcomes of the analysis of the first mode shape frequency at different levels of variable $\mathrm{x}$

\begin{tabular}{cccccc}
\hline No. trial & $\boldsymbol{L}$ & $\boldsymbol{y}$ & $\boldsymbol{t}$ & $\boldsymbol{x}$ & Fre \\
\hline $\mathbf{1}$ & 8 & 1.2 & 1 & 4.5 & 47.468 \\
$\mathbf{2}$ & 8 & 1.2 & 1 & 5.0 & 48.99 \\
$\mathbf{3}$ & 8 & 1.2 & 1 & 5.5 & 50.731 \\
\hline
\end{tabular}

\subsection{Analysis signal to noise ratio}

The outcome of signal to noise and means analysis is presented in Figure 10 and Table 4. This figure and Table indicated that optimum levels of the design variables are the maximum values of signal to noise value. Whereby, optimal levels of the design variables are L3y3t3x3, with a signal to noise values of variables $\mathrm{L}, \mathrm{y}, \mathrm{t}, \mathrm{x}$ are $36.03,37.66,36.44$, and 36.02 , respectively. The optimal values of the first modal shape frequency are 85.2688. response table form means are used to the calculated predicted value of the 
first modal shape frequency. Table 6 shows the outcomes of the analysis of the first mode shape frequency at different levels of variable x. Table 7 presents Orthogonal arrays, FEM results, predicted results of the regression equation, and error. Table 8 demonstrates the signal to noise ratios and means.

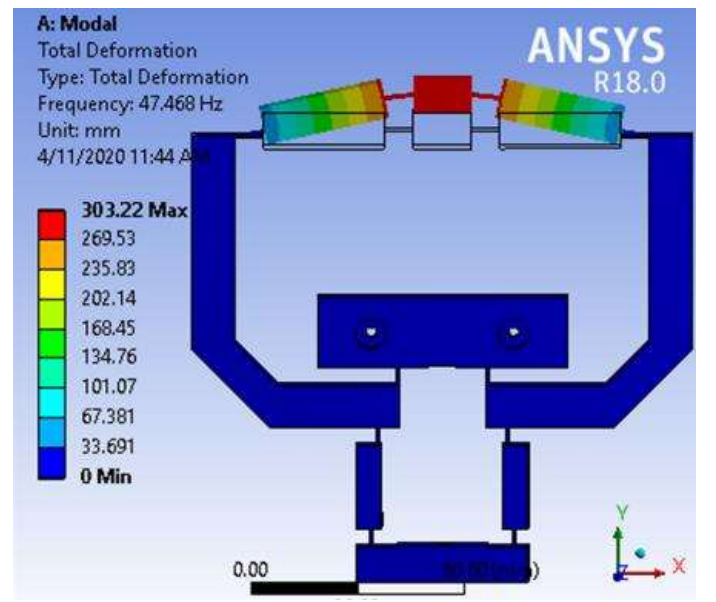

a) $\mathrm{x}=4.5 \mathrm{~mm}$

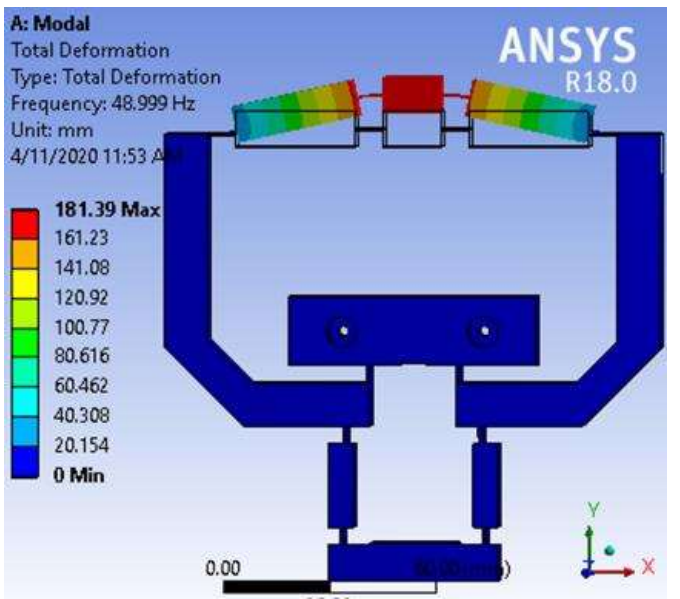

b) $\mathrm{x}=5.5 \mathrm{~mm}$

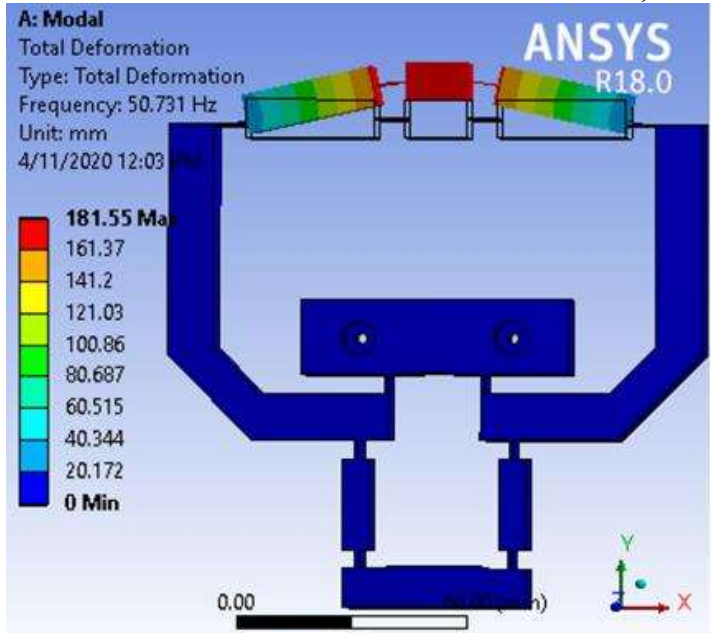

c) $\mathrm{x}=6.5 \mathrm{~mm}$

Figure 9. Effect of variable $\mathrm{x}$ on displacement

Table 7. Orthogonal arrays, FEM results, predicted results of regression equation and error

\begin{tabular}{cccccccc}
\hline $\begin{array}{c}\text { No. } \\
\text { Trial }\end{array}$ & $\boldsymbol{L}$ & $\boldsymbol{y}$ & $\boldsymbol{t}$ & $\boldsymbol{x}$ & $\begin{array}{c}\text { FEM results } \\
\text { of Fre (Hz) }\end{array}$ & $\begin{array}{c}\text { Predicted results of recreation } \\
\text { equation of Fre (Hz) }\end{array}$ & $\begin{array}{c}\text { Error } \\
(\%)\end{array}$ \\
\hline 1 & 8 & 1.2 & 1 & 4.5 & 47.422 & 44.954 & 5.20 \\
2 & 8 & 1.2 & 1.5 & 5 & 50.604 & 49.377 & 2.42 \\
3 & 8 & 1.2 & 2 & 5.5 & 52.930 & 54.007 & -2.03 \\
4 & 8 & 2.4 & 1 & 5 & 56.798 & 57.645 & -1.49 \\
5 & 8 & 2.4 & 1.5 & 5.5 & 63.887 & 62.64 & 1.95 \\
6 & 8 & 2.4 & 2 & 4.5 & 64.263 & 64.844 & -0.90 \\
7 & 8 & 3.6 & 1 & 5.5 & 70.865 & 71.912 & -1.48 \\
8 & 8 & 3.6 & 1.5 & 4.5 & 71.620 & 74.273 & -3.70 \\
\hline
\end{tabular}




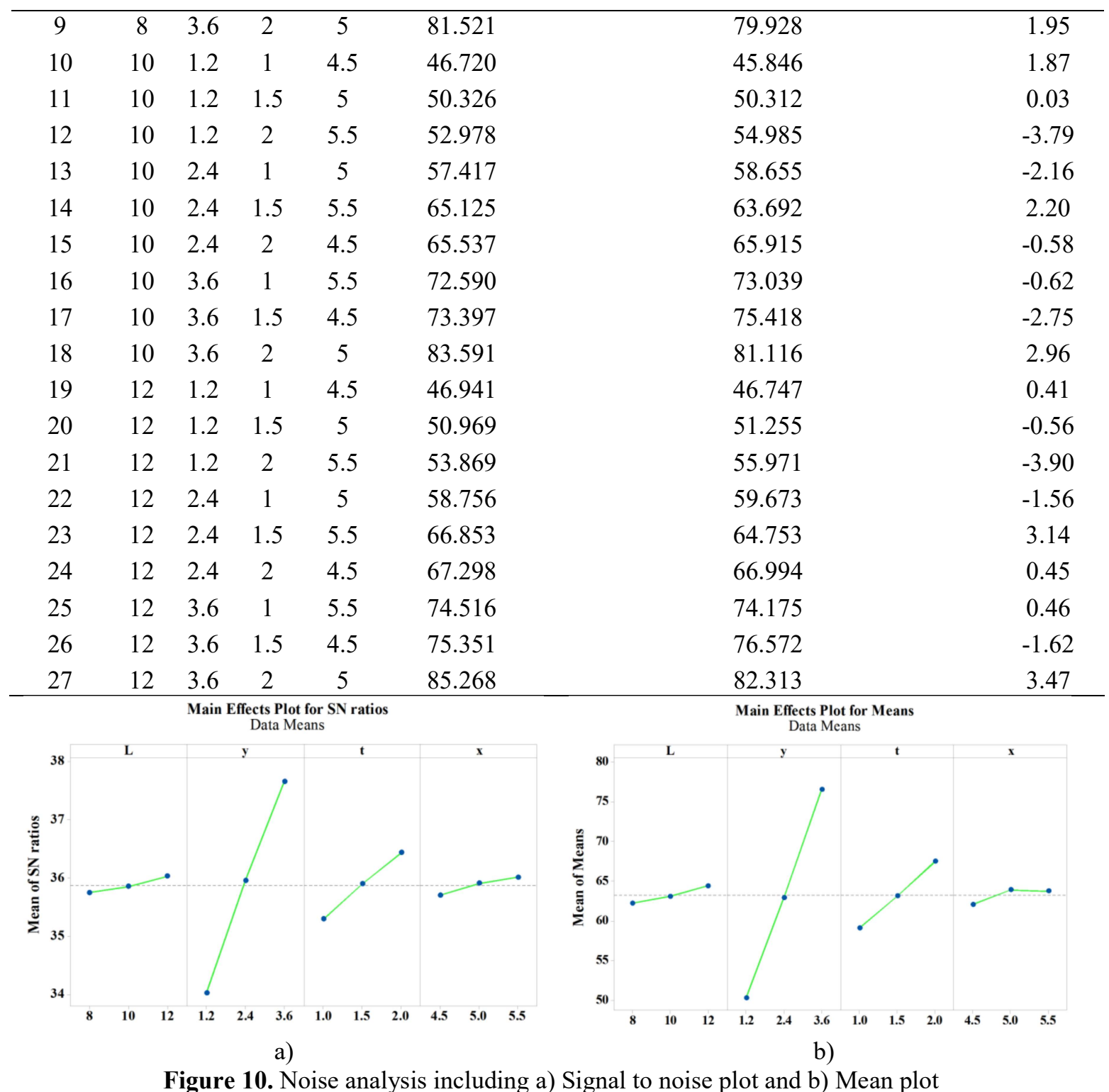

Table 8. Signal to noise ratios and means

Response table for the signal to noise ratios

\begin{tabular}{ccccc}
\hline Level & $\boldsymbol{L}$ & $\boldsymbol{y}$ & $\boldsymbol{t}$ & $\boldsymbol{x}$ \\
\hline 1 & 35.75 & 34.02 & 35.30 & 35.71 \\
2 & 35.85 & 35.95 & 35.90 & 35.91 \\
3 & 36.03 & 37.66 & 36.44 & 36.02 \\
Delta & 0.28 & 3.64 & 1.14 & 0.31 \\
Rank & 4 & 1 & 2 & 3 \\
\hline
\end{tabular}

Response table for means

\begin{tabular}{ccccc}
\hline Level & $\boldsymbol{L}$ & $\boldsymbol{y}$ & $\boldsymbol{t}$ & $\boldsymbol{x}$ \\
\hline 1 & 62.21 & 50.31 & 59.11 & 62.06 \\
2 & 63.08 & 62.88 & 63.13 & 63.92 \\
3 & 64.43 & 76.53 & 67.48 & 63.73 \\
Delta & 2.22 & 26.22 & 8.36 & 1.86 \\
Rank & 3 & 1 & 2 & 4 \\
\hline
\end{tabular}




\subsection{Analysis of variance}

Table 9 Analysis of variance for transformed response

\begin{tabular}{cccccccc}
\hline Source & DF & Seq SS & Contribution & Adj SS & Adj MS & F-Value & P-Value \\
\hline Regression & 4 & 13.6628 & $98.30 \%$ & 13.6628 & 3.4157 & 317.87 & 0.000 \\
L & 1 & 0.0790 & $0.57 \%$ & 0.0790 & 0.0790 & 7.35 & 0.013 \\
y & 1 & 12.2921 & $88.44 \%$ & 12.2921 & 12.2921 & 1143.92 & 0.000 \\
t & 1 & 1.2239 & $8.81 \%$ & 1.2239 & 1.2239 & 113.90 & 0.000 \\
x & 1 & 0.0677 & $0.49 \%$ & 0.0677 & 0.0677 & 6.30 & 0.020 \\
Error & 22 & 0.2364 & $1.70 \%$ & 0.2364 & 0.0107 & & \\
Total & 26 & 13.8992 & $100.00 \%$ & & & & \\
\hline $0 \%$, R-square (adj) $=97.99 \%$, R-square (pred) $=97.34 \%$ & & &
\end{tabular}

The results of the analysis of variance as depicted in Table 5 , proved that design variables have significantly contributed to the first modal shape frequency and specific contribution of variables $\mathrm{L}, \mathrm{y}, \mathrm{t}, \mathrm{x}$ are $0.57 \%$, $88.44 \%, 8.81 \%, 0.49 \%$, respectively. The F-values and $\mathrm{P}$-values are contented with requests larger than 2 and less than 0.05 . Table 9 presents the analysis of variance for transformed response

\subsection{Analysis of regression equation}

$$
\text { Fre }=(4.540+0.0331 \mathrm{~L}+0.6886 \mathrm{y}+0.5215 \mathrm{t}+0.1227 \mathrm{x})^{2}
$$

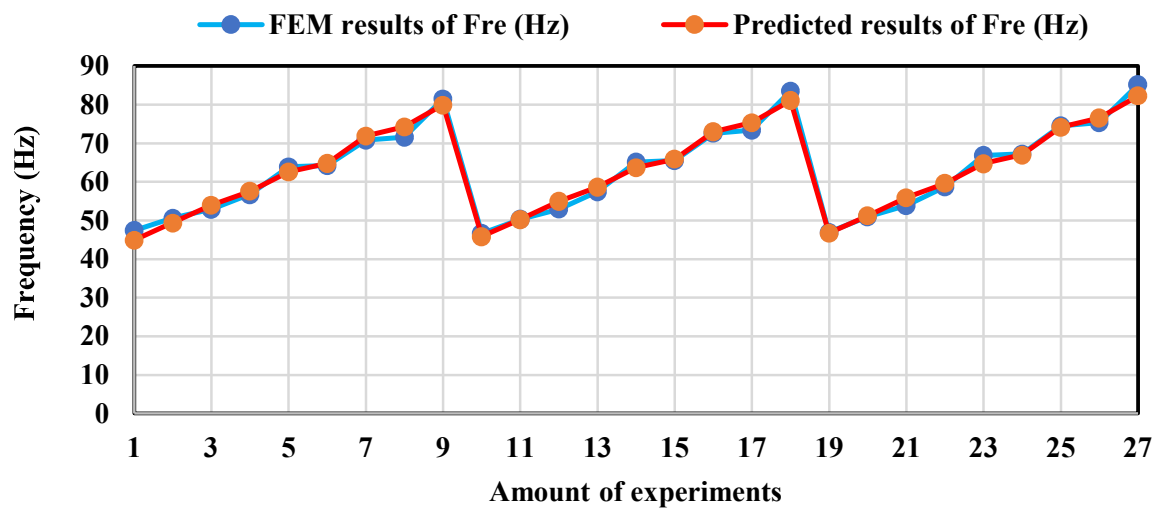

Figure 11. compared between FEM results and predicted results of Fre

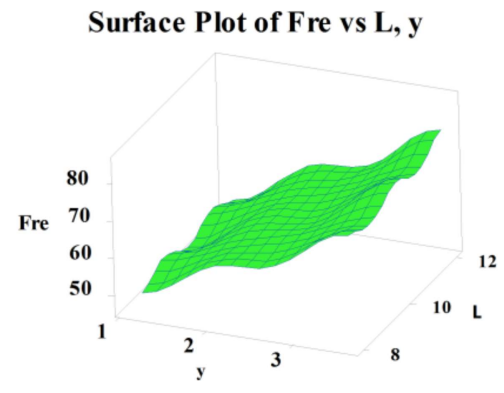

a) Plot vs L, y

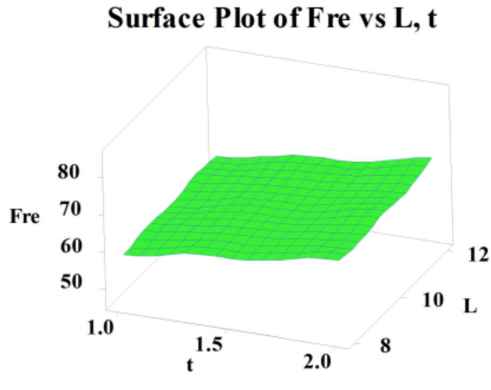

b) Plot vs L, t
Surface Plot of Fre vs $L, x$

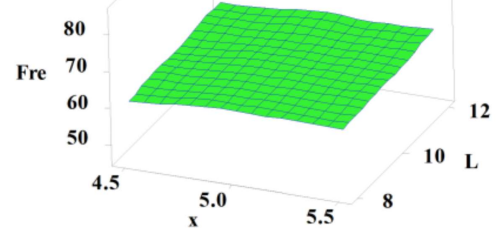

c) Plot vs L, $\mathrm{x}$

Figure 12. Surface Plot 
The regression equation was obtained by using Minitab 18.0. The graph of Fre as illustrated in Figure 11, is obtained by using the values in Table 3. Table 3 and Figure 11 prove that the predicted values and simulation values are approximate with an error deviation percent interval $-4 \%$ to $5 \%$. The results are good to agree with.

The graph of the surface plot as presented in Figure 11(a) indicated when variable L increases from $8 \mathrm{~mm}$ to $12 \mathrm{~mm}$ and variable y increases from $1.2 \mathrm{~mm}$ to $3.6 \mathrm{~mm}$, Fre increases from $50 \mathrm{~Hz}$ to over $85 \mathrm{~Hz}$. Similarly, in Figure 11(b) when variable $\mathrm{L}$ and t increase from $8 \mathrm{~mm}$ to $10 \mathrm{~mm}$ and $1 \mathrm{~mm}$ to $2 \mathrm{~mm}$, Fre increases from $50 \mathrm{~Hz}$ to $80 \mathrm{~Hz}$. In Figure 11(c), when variable $\mathrm{L}$ and $\mathrm{x}$ increases from $8 \mathrm{~mm}$ to $10 \mathrm{~mm}$ and $4.5 \mathrm{~mm}$ to $5.5 \mathrm{~mm}$, Fre increases from $60 \mathrm{~Hz}$ to $80 \mathrm{~Hz}$. The first modal shape always increases when variables $\mathrm{L}, \mathrm{t}, \mathrm{x}$ increase. Figure 12 shows the surface plot of the difference of a couple of parameters with frequency.

\subsection{Predicted and confirmation}

$$
\begin{aligned}
& \mu_{\text {Fre }}=\text { Fre }_{m}+\sum_{i=1}^{q}\left(\text { Fre }_{0 i}-\text { Fre }_{m}\right)=L 3+y 3+t 3+x 3-3 F e_{m} \\
& \mu_{\text {Fre }}=64.43+76.53+67.48+63.73-3^{*} 63.237=82.459(\mathrm{~Hz}) \\
& C I_{C E}= \pm \sqrt{F_{\alpha}(1, f e) \operatorname{Ve}\left(\frac{1}{n_{\text {eff }}}+\frac{1}{R_{e}}\right)}
\end{aligned}
$$

At confidence interval 95\%, error interval is determined as following:

$$
\begin{aligned}
& \text { At } \alpha=0.05, \mathrm{fe}=22, \mathrm{~F}_{0.05}(1,22)=4.3009 \quad[26], \mathrm{Ve}=0.0107, \mathrm{R}=4, \mathrm{Re}=1, \mathrm{n}=27 . \\
& { }_{C I}= \pm \sqrt{\frac{4.3009 \times 0.0107 \times\left(\frac{1}{\frac{27}{1+4}}+1\right)}{\sqrt{1+4}}}= \pm 0.233,82.225<\mu_{\text {confirmation }}<82.693
\end{aligned}
$$

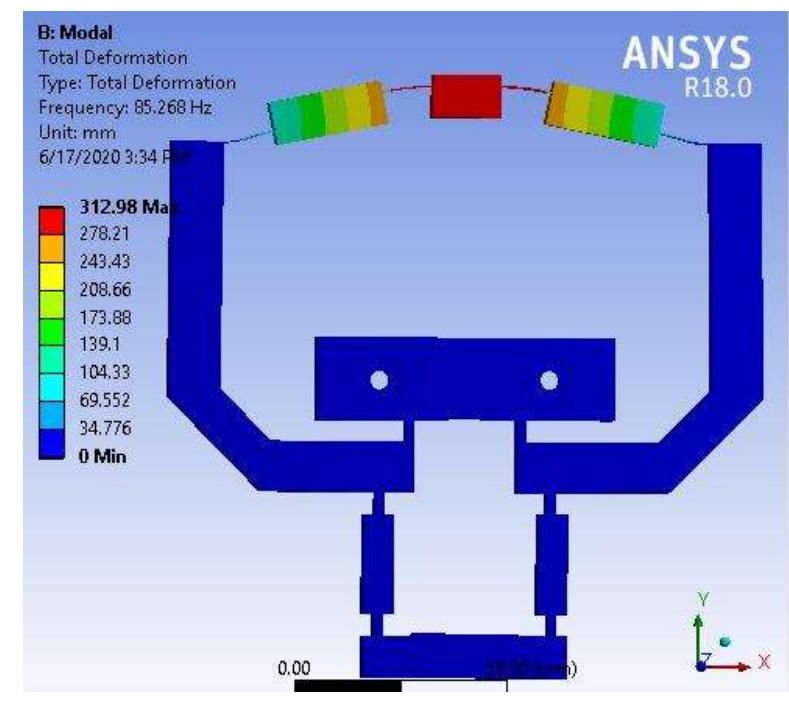

Figure 13. The optimal outcome of the first modal shape frequency

The optimum outcome of Fre was obtained $85.268 \mathrm{~Hz}$ by simulation at an optimal level of the variables L3y3t3x3. The predicted value of the Fre of Taguchi method achieved $82.459 \mathrm{~Hz}$. The error deviation percent of the predicted and optimal values of the regression equation and the Taguchi method is $3.47 \%$ and $3.29 \%$, respectively. The outcomes are good to agree and the Taguchi method and regression equation 
allowed applying to optimize a single objective. Figure 13 presents the optimal outcome of the first modal shape frequency after the optimization process.

\section{CONCLUSIONS}

More generally, these basic findings are consistent with research showing that the outcome analysis of the finite element method in ANSYS indicated that the first modal shape frequency is strongly affected by design variables, therein variable y has significantly affected and was confirmed by analysis of the signal to noise and analysis of variance. The outcomes regression analysis and the Taguchi method proved that FEM values and the values of the regression equation and the Taguchi method are good to agree with error deviation percent are less than $4 \%$. This allows the conclusion that the optimal outcome obtains the new flexible displacement amplifier mechanism has the maximum of first modal shape is $85.268 \mathrm{~Hz}$ at an optimal level of combination design variables L $3 y 3 \mathrm{t} 3 \times 3$ specific the values of variables $\mathrm{L}, \mathrm{y}, \mathrm{t}$ and $\mathrm{x}$ are 12 $\mathrm{mm}, 3.6 \mathrm{~mm}, 2 \mathrm{~mm}$ and $5.5 \mathrm{~mm}$. This provides a good starting point for discussion and further research and future investigations are necessary to validate the kinds of conclusions that can be drawn from this study.

\section{REFERENCES}

[1] Y. K. Yong and T.-F. Lu, "Kinetostatic modeling of 3-RRR compliant micro-motion stages with flexure hinges," Mechanism and Machine Theory, vol. 44, no. 6, pp. 1156-1175, 2009.

[2] U. Bhagat et al., "Design and analysis of a novel flexure-based 3-DOF mechanism," Mechanism and Machine Theory, vol. 74, pp. 173-187, 2014.

[3] Y. Tian, B. Shirinzadeh, and D. Zhang, "Design and dynamics of a 3-DOF flexure-based parallel mechanism for micro/nano manipulation," Microelectronic Engineering, vol. 87, no. 2, pp. 230-241, 2010.

[4] Q. Xu and Y. Li, "Analytical modeling, optimization and testing of a compound bridge-type compliant displacement amplifier," Mechanism and Machine Theory, vol. 46, no. 2, pp. 183-200, 2011.

[5] N.-T. Huynh, S.-C. Huang, and T.-P. Dao, "Optimal displacement amplification ratio of bridge-type compliant mechanism flexure hinge using the Taguchi method with grey relational analysis," Microsystem Technologies, 2018.

[6] N. C. Vu, N. T. Huynh, and S. C. Huang, "Optimization the first frequency modal shape of a tensural displacement amplifier employing flexure hinge by using Taguchi Method," Journal of Physics: Conference Series, vol. 1303, p. 012016, 2019.

[7] C. N. Wang, K. P. Truong, N. T. Huynh, and H. Nguyen, "Optimization on effects of design parameter on displacement amplification ratio of 2 DOF working platform employing Bridge-type compliant mechanism flexure hinge using Taguchi method," Journal of Physics: Conference Series, vol. 1303, p. 012053, 2019.

[8] C. N. Wang, K. P. Truong, N. T. Huynh, and L. Q. Nhat Hoang, "Optimization effects of design parameter on the first frequency modal of a Bridge-type compliant mechanism flexure hinge by using the Taguchi method," Journal of Physics: Conference Series, vol. 1303, p. 012063, 2019.

[9] N.-T. Huynh, S.-C. Huang, and T.-P. Dao, "Design variables optimization effects on acceleration and contact force of the double sliders-crank mechanism having multiple revolute clearance joints by use of the Taguchi method based on a grey relational analysis," Sādhanā, vol. 45, no. 1, 2020.

[10] N.-T. H. Viet-Hung Hoang, Ho Nguyen, Shyh-Chour Huang, "Analysis and optimal design a new flexible hinge displacement amplifier mechanism by using Finite element analysis based on Taguchi method," 2019 IEEE Eurasia Conference on IOT, Communication and Engineering, 2020.

[11] Q. Li, C. Pan, and X. Xu, "Closed-form compliance equations for power-function-shaped flexure hinge based on unit-load method," Precision Engineering, vol. 37, no. 1, pp. 135-145, 2013.

[12] N. Lobontiu and M. Cullin, "In-plane elastic response of two-segment circular-axis symmetric notch flexure hinges: The right circular design," Precision Engineering, vol. 37, no. 3, pp. 542-555, 2013.

[13] K.-q. Qi, Y. Xiang, C. Fang, Y. Zhang, and C.-s. Yu, "Analysis of the displacement amplification ratio of bridge-type mechanism," Mechanism and Machine Theory, vol. 87, pp. 45-56, 2015.

[14] L. Qiu, S. Yin, and Z. Xie, "Failure analysis and performance comparison of Triple-LET and LET flexure hinges," Engineering Failure Analysis, vol. 66, pp. 35-43, 2016.

[15] Y. Tian, B. Shirinzadeh, and D. Zhang, "Closed-form compliance equations of filleted V-shaped flexure hinges for compliant mechanism design," Precision Engineering, vol. 34, no. 3, pp. 408-418, 2010. 
[16] M. Yang, Z. Du, and W. Dong, "Modeling and analysis of planar symmetric superelastic flexure hinges," Precision Engineering, vol. 46, pp. 177-183, 2016.

[17] M. Ling, J. Cao, Z. Jiang, and J. Lin, "A semi-analytical modeling method for the static and dynamic analysis of complex compliant mechanism," Precision Engineering, 2017.

[18] S. B. Choi, S. S. Han, Y. M. Han, and B. S. Thompson, "A magnification device for precision mechanisms featuring piezoactuators and flexure hinges: Design and experimental validation," Mechanism and Machine Theory, vol. 42, no. 9, pp. 1184-1198, 2007.

[19] Y. Tian, B. Shirinzadeh, D. Zhang, and Y. Zhong, "Three flexure hinges for compliant mechanism designs based on dimensionless graph analysis," Precision Engineering, vol. 34, no. 1, pp. 92-100, 2010.

[20] K. Cai, Y. Tian, F. Wang, D. Zhang, and B. Shirinzadeh, "Development of a piezo-driven 3-DOF stage with T-shape flexible hinge mechanism," Robotics and Computer-Integrated Manufacturing, vol. 37, pp. 125-138, 2016.

[21] L.-J. Lai and Z.-N. Zhu, "Design, modeling and testing of a novel flexure-based displacement amplification mechanism," Sensors and Actuators A: Physical, vol. 266, pp. 122-129, 2017.

[22] G. Chen, Y. Ma, and J. Li, "A tensural displacement amplifier employing elliptic-arc flexure hinges," Sensors and Actuators A: Physical, vol. 247, pp. 307-315, 2016.

[23] S. Kumar, A. Batish, R. Singh, and T. P. Singh, "A hybrid Taguchi-artificial neural network approach to predict surface roughness during electric discharge machining of titanium alloys," Journal of Mechanical Science and Technology, vol. 28, no. 7, pp. 2831-2844, 2014.

[24] V. K. Vankanti and V. Ganta, "Optimization of process parameters in drilling of GFRP composite using Taguchi method," Journal of Materials Research and Technology, vol. 3, no. 1, pp. 35-41, 2014.

[25] N. Celik, G. Pusat, and E. Turgut, "Application of Taguchi method and grey relational analysis on a turbulated heat exchanger," International Journal of Thermal Sciences, vol. 124, pp. 85-97, 2018.

[26] R. K. Roy, " A primer on the Taguchi method " Society of Manufacturing Engineers, 2010.

Ngày nhận bài:09/07/2020

Ngày chấp nhận đăng:30/12/2020 